\title{
Editorial: Integrating Emerging Technologies Into Marine Megafauna Conservation Management
}

\author{
Peter H. Dutton ${ }^{1 *}$, Lisa Komoroske ${ }^{2}$, Lars Bejder ${ }^{3,4,5}$ and Mark Meekan ${ }^{6}$ \\ ${ }^{1}$ NOAA Fisheries, Southwest Fisheries Science Center, La Jolla, CA, United States, ${ }^{2}$ Department of Environmental \\ Conservation, University of Massachusetts, Amherst, MA, United States, ${ }^{3}$ Aquatic Megafauna Research Unit, Centre for \\ Sustainable Aquatic Ecosystems, Harry Butler Institute, Murdoch University, Murdoch, WA, Australia, ${ }^{4}$ Marine Mammal \\ Research Program, Hawaii Institute of Marine Biology, University of Hawai'i at Manoa, Kaneohe, HI, United States, \\ ${ }^{5}$ Zoophysiology, Department of Bioscience, Aarhus University, Aarhus, Denmark, ${ }^{6}$ Australian Institute of Marine Science, \\ Crawley, WA, Australia
}

Keywords: technology, megafauna, conservation, wildlife, human impacts

\section{Editorial on the Research Topic}

\section{Integrating Emerging Technologies into Marine Megafauna Conservation Management}

Many recent and emerging technological innovations hold great potential to transform the "best-available science" for marine megafauna conservation management, such as remote sensing, telemetry, molecular technologies, unmanned aerial vehicles, bio-acoustics, and animal-borne imaging (O’Brien, 2015; Nowacek et al., 2016; Hays and Hawkes, 2018; Harcourt et al., 2019). This includes both the use of these technologies to address key knowledge gaps in species' biology required for management decisions (e.g., critical habitat use, demographic vital rates, and population connectivity), as well as their application to identify and mitigate human impacts (e.g., distinguishing impact hotspots and forecasting interactions). These technologies are being

\section{OPEN ACCESS}

Edited and reviewed by:

Graeme Clive Hays,

Deakin University, Australia

*Correspondence:

Peter H. Dutton

peter.dutton@noaa.gov

Specialty section:

This article was submitted to

Marine Megafauna,

a section of the journal

Frontiers in Marine Science

Received: 17 September 2019

Accepted: 28 October 2019

Published: 19 November 2019

Citation:

Dutton PH, Komoroske L, Bejder L and Meekan M (2019) Editorial:

Integrating Emerging Technologies Into Marine Megafauna Conservation Management. Front. Mar. Sci. 6:693.

doi: 10.3389/fmars.2019.00693 increasingly employed across a broad diversity of wildlife research contexts; however, there has been highly variable efficacy integrating these new tools into conservation science and translating results into successful management practices and policies (Berger-Tal and Lahoz-Monfort, 2018).

In this special Research Topic, researchers submitted articles addressing how recent and emerging technological innovations are being used to answer the key outstanding biological questions for marine megafauna. The resulting 17 articles illustrate how novel information from different technological applications is informing marine megafauna conservation and discuss challenges, future directions and remaining technological gaps.

\section{BIO-ACOUSTICS}

The collection of passive acoustic data is a rapidly evolving field that is helping to enhance the ability to accurately estimate abundance and determine distribution of marine mammals, particularly for rare or elusive species (Marques et al., 2013). The case study presented by Hildebrand et al. illustrates how passive acoustic monitoring can be applied to detect and analyze signals from two different species of sperm whales (Kogia spp.) to obtain estimates of population density in the Gulf of Mexico (GOM).

\section{GENETIC AND OTHER MOLECULAR ANALYSES}

Collecting non-invasive samples for genetic analysis to identify species, subspecies, or stocks of marine megafauna at sea remains challenging. Baker et al. demonstrate how eDNA methods can be 
used to detect specific communities of killer whales, and validate a method that will be useful for collecting DNA from the wake of whales.

Meekan et al. describe an invertebrate DNA (iDNA) approach whereby DNA from whale sharks (Rhincodon typus) was obtained from skin attached to copepods they removed to study population structure in elasmobranchs. McInnes et al. used DNA metabarcoding of black-browed albatross (Thalassarche melanophris) scats as a non-invasive method to identify the variety of fish species found in the diet of seabirds, and discuss uses of this approach to evaluate the extent of scavenging interaction with fishery discards.

The use of stable isotopes has become a valuable technique to understand the biogeography and foraging habits of marine species, while hormone analyses provide a means to assess reproduction, nutrition, stress, and health of individuals and in populations. Fleming et al. explore how combining these two approaches can better inform future marine megafauna conservation and management efforts. They identify four broad areas of research that will require methodological developments.

Lysiak et al. combined stable isotope analysis with analyses of steroid and thyroid hormones on samples from a drowned North Atlantic right whale (Eubalaena glacialis) to illustrate how key physiological indicators traced from baleen can be used to identify the recent anthropogenic impacts on these threatened whale populations.

Meyer et al. evaluated the use of lipid and fatty acid analyses on white sharks, Carcharodon carcharias, for gaining insights into the trophic ecology of marine elasmobranchs.

\section{AUTONOMOUS UNDERWATER VEHICLES (AUVs)}

Technological advances in autonomous underwater vehicles (AUVs) enable direct observation of underwater behaviors and habitats of marine megafauna.

Dodge et al. describe a "smart" AUV that allows direct observation of free-swimming marine animals by concurrently recording video, localization, depth, and environmental data. They use this technology to characterize the diving behavior, foraging ecology, and habitat use of leatherback turtles (Dermochelys coriacea) in a coastal habitat impacted by anthropogenic hazards to inform conservation and management planning.

\section{UNMANNED AERIAL VEHICLES (UAVs) OR SYSTEMS (UASs)}

Drones, UAVs, or UASs have great potential for overcoming challenges of collecting samples from animals in the wild. Pirotta et al. developed customized UAV to sample "whale blow," from free-swimming humpback whales (Megaptera novaeangliae), to carry out a population health assessment based on microbiota composition determined to be present in respiratory tracts using genetic sequencing. This study describes a promising new tool for monitoring health in marine megafauna, however the potentia disturbance of these systems on marine megafauna are unknown.

Ramos et al. assessed the responses of bottlenose dolphins (Tursiops truncatus) and manatees (Trichechus manatus manatus) to UAS surveillance flight and discuss guidelines that could be developed to minimize animal disturbance.

\section{SATELLITE TELEMETRY}

Dewar et al. Provide new insights on movements, behaviors and habitat use by basking sharks (Cetorhinus maximus) off the coast of California, by analyzing data from pop-off satellite archival transmitting (PSAT) and oceanographic data. They discuss how shifts in vertical and horizontal movement patterns likely reflect changes in prey availability and oceanographic conditions. In order to overcome limitations of using light-based geolocation technology on basking sharks that spend most of their time in deep waters below the photic zone, Braun et al. analyzed depthtemperature profile data recorded by PSAT tags in combination with high resolution models of in situ oceanographic data to determine movement patterns in the NW Atlantic. Both basking shark studies found evidence of long-range movement that illustrates the importance of international cooperation for effective conservation strategies for this threatened species.

Horton et al. provide an extensive analysis of satellite telemetry movement data across vast geographic ranges that shows a fidelity with respect to migratory routes that is associated with gravitational and magnetic coordinates for marine megafauna, including great white sharks ( $C$. carcharias), northern elephant seals (Mirounga angustirostris), and humpback whales (M. novaeangliae).

\section{OCEAN NOISE MODELING TOOLS}

Underwater vessel-generated noise can interfere with the ability of marine mammals to communicate and detect prey. Gabriele et al. examined the ability of harbor seals and humpback whales to communicate with conspecifics under various ambient noise scenarios as a step toward developing tools to assess and mitigate anthropogenic noise.

\section{SPECIES DISTRIBUTION AND HABITAT MODELING}

Determining the spatial and temporal distributions of marine megafauna species is an important challenge in marine megafauna research and conservation. Brodie et al. highlight the utility of including dynamic subsurface variables to improve performance of species distribution models to characterize habitat use of pelagic predators, including blue sharks (Prionace glauca), shortfin mako sharks (Isurus oxyrinchus), common thresher sharks (Alopias vulpinus), and swordfish (Xiphias gladius), in the California Current.

Horton et al. present results of thermographic research that illustrates the potential of infrared videography with various post-processing analytical approaches of 
thermographic data to create automated platforms for whale detection. They discuss how advances in these technologies provide a non-invasive approach to identify species, collect information for monitoring distributions of cetaceans in remote marine habitats, and reduce ship-strikes in high traffic areas.

Finally, Lewison et al. discuss several emerging technologies that incorporate approaches that account for complexity of ocean systems to address fisheries bycatch and highlight opportunities for advancing marine megafauna research and conservation.

\section{REFERENCES}

Berger-Tal, O., and Lahoz-Monfort, J. J. (2018). Conservation technology: the next generation. Cons. Lett. 11:e12458. doi: 10.1111/conl.12458

Harcourt, R., Sequeira, A. M. M., Zhang, X., Roquet, F., Komatsu, K., Heupel, M., et al. (2019). Animal-borne telemetry: an integral component of the ocean observing toolkit. Front. Mar. Sci. 6:326. doi: 10.3389/fmars.2019. 00326

Hays, G. C., and Hawkes, L. A. (2018). Satellite tracking sea turtles: opportunities and challenges to address key questions. Front. Mar. Sci. 5:432. doi: 10.3389/fmars.2018.00432

Marques, T. A., Thomas, L., Martin, S. W., Mellinger, D. K., Ward, J. A., Moretti, D. J., et al. (2013). Estimating animal population density using passive acoustics, Biol. Rev. 88, 287-309. doi: 10.1111/brv.12001

Nowacek, D. P., Christiansen, F., Bejder, L., Goldbogen, J. A., and Friedlaender, A. (2016). Studying cetacean behavior: new technological
Collectively the studies in this Special Topic illustrate advances in the application of some technologies to marine megafauna conservation. These, and additional emerging technologies will continue to evolve and provide opportunities for further innovation.

\section{AUTHOR CONTRIBUTIONS}

All authors listed have made a substantial, direct and intellectual contribution to the work, and approved it for publication.

approaches and conservation implications. Anim. Behav. 120, 235-244. doi: 10.1016/j.anbehav.2016.07.019

O'Brien, J. (2015). Perspective: technologies for conserving biodiversity in the Anthropocene. Issues Sci. Technol. 32, 91-97.

Conflict of Interest: The authors declare that the research was conducted in the absence of any commercial or financial relationships that could be construed as a potential conflict of interest.

Copyright (c) 2019 Dutton, Komoroske, Bejder and Meekan. This is an open-access article distributed under the terms of the Creative Commons Attribution License (CC $B Y)$. The use, distribution or reproduction in other forums is permitted, provided the original author(s) and the copyright owner(s) are credited and that the original publication in this journal is cited, in accordance with accepted academic practice. No use, distribution or reproduction is permitted which does not comply with these terms. 